\title{
Role of natural herbs and phytochemicals to minimize tumor and economic burden in breast cancer treatment
}

This article was published in the following Dove Press journal:

Breast Cancer - Targets and Therapy

7 December 2016

Number of times this article has been viewed

\author{
Maria Shoaib' \\ Syed Ahsanuddin Ahmed ${ }^{2}$ \\ 'Dow Medical College, Dow \\ University of Health Sciences, Karachi, \\ ${ }^{2}$ Sindh Medical College, Jinnah Sindh \\ Medical University, Karachi, Pakistan
}

\section{Dear editor}

We read the article "Economic burden related to chemotherapy-related adverse events in patients with metastatic breast cancer in an integrated health care system" by Rashid et al with great interest and would like to add some views in its support. ${ }^{1}$

Carcinoma of breast is the most common malignancy in females worldwide, contributing to one third of almost all known neoplasm. It is the second leading cause of mortality in females. As per a public survey it is estimated that globally more than 1,000,000 women are diagnosed with breast cancer annually, and 410,000 affected women do not survive. This cancer is also known to cause substantial psychological and economical burden on the patient and their families. ${ }^{2,3}$

Indeed, the economic burden of approximately $>$ US $\$ 572$ million is huge. Fortunately breast cancer has good survival outcomes, but with the probability of costly treatment. To cure breast cancer, various expensive therapeutic regimens including cycles of chemotherapy, cancer gene receptor therapy, radiation, and surgery, and complex diagnostic modalities such as radio imaging and identification of oncogene and tumor markers, are used. The morbid adverse effects of cytotoxic anticancer drugs or radiation often lead to unanticipated hospitalization and follow-up visits with additional laboratory work, imaging, and medications to treat adverse events augmenting economic burden on the patient and the health care system. Newer, targeted therapies and personalized medicine are pricier but may reduce repeated detrimental events, improving adherence and potentiating chances of overall patient survival. ${ }^{1}$

There is scientific evidence that various dietary herbs and plant products are cancer preventive. Phytochemical compounds have shown anticancer potential acting via biological pathways and modulating immune systems to lessen neoplastic growth. They trigger immune cells such as natural killer (NK) cells, cytotoxic T cells, chemokines, and tumor necrosis factor- $\alpha$; by virtue of this quality they can be promising alternate/ adjuvant options for therapeutic or preventive strategies for breast cancers. Apart from being effective and less toxic they complement conventional chemotherapeutic drugs and also are able to counterbalance any repetitive resistance to hormonal and targeted therapy. This can thus help reducing chances of adverse events and aiding in alleviation of patients' tumors and economic burden. ${ }^{4,5}$
Dow Medical College, Dow University of Health Sciences, I76/Y Block 2 PECHS

Karachi, Pakistan

Tel +923333289909

Email syedamariashoaib@gmail.com 
Extracts and juices of medicinal plants like Withania somnifera (rennet), Aphanamixis polystachya (Pithraj tree), Dysoxylum binectariferum (rosewoods), Vaccinium macrocarpon (cranberry), Glycyrrhiza glabra (liquorice), Uncaria tomentosa (cat's claw), Panax ginseng (ginseng), Prunus armenaica (apricot), Echinacea (cone flower), Hedyotis diffusa (Oldenlandia), and Arctium lappa (greater burdock) possess bioactive immunomodulators as their main constituents producing the anticancer effects via activation of lymphocytes (epigallocatechin-3-gallate, $\beta$-carotene, quinic acid, and ginsan) and anti-inflammatory agents (curcumin, glabridin, arctigenin, and ajoene). ${ }^{5}$

Bioactive composites obtained from dietary sources such as fish in the form of omega-3 fatty acids; resveratrol (3,5,40-trihydroxy-transstilbene); naturally occurring phytoalexin in grapes; and epigallocatechin gallate a polyphenolic compound found in green tea and fruit like red dates (ziziphus jujube) are rich in antioxidant properties, by stimulating protective enzymes such as glutathione transferase, and prevent the neoplastic proliferation. The volatile oils and extracts of herbs in the kitchen cupboard like Allium sativum (garlic), Curcuma longa (turmeric), Camellia sinensis (tea plant) and flax seed inhibit formation of mevalonate that lessens the cholesterol synthesis and tumor growth. This induces anti-proliferating and apoptotic effects in various breast cancer cell lines promoting the herbs potential use for inhibiting carcinogenesis. ${ }^{5,6}$

Knowledge of dietary compounds and traditionally used medicinal herbs having possible preventive and curative effects on cancer, may rationalize further translational application. We emphasize the importance of a remedial portfolio of natural bioactive compounds for treating breast cancer, and it's prevention. Clinical trials and attempts to characterize these plants and their extracts will surely help to reduce economic burden from costly chemotherapy and cancer receptor gene therapy, and create a breakthrough in the world of medicine by helping many underprivileged, and those who cannot afford treatment.

\section{Acknowledgments}

The authors thank Navaira Shoaib, Natasha Najam, and Raad Najam for their help in literature search. The authors also thank Mrs Rizwana Ataullah who suggested this literature search and from whom they got the idea to write this paper.

\section{Disclosure}

The authors declare no conflict of interest in this communication.

\section{References}

1. Rashid N, Koh H, Baca H, Lin K, Malecha S, Masaquel A. Economic burden related to chemotherapy-related adverse events in patients with metastatic breast cancer in an integrated health care system. Breast Cancer (Dove Med Press). 2016;8:173-181.

2. Coughlin SS, Ekwueme DU. Breast cancer as a global health concern. Cancer Epidemiol. 2009;33(5):315-318.

3. Sufian SN, Masroor I, Mirza W, Butt S, Afzal S, Sajjad Z. Evaluation of common risk factors for breast carcinoma in females: a hospital based study in Karachi, Pakistan. Asian Pac J Cancer Prev. 2014;16(15): 6347-6352.

4. Baraya YU, Wong KK, Yaacob NS. The immunomodulatory potential of selected bioactive plant-based compounds in breast cancer: a review. Anticancer agents Med Chem. Epub 2016 August 17.

5. Bonofiglio D, Giordano C, De Amicis F, Lanzino M, Andò S. Natural products as promising antitumoral agents in breast cancer: mechanisms of action and molecular targets. Mini Rev Med Chem. 2016;16(8):596-604.

6. Shareef M, Ashraf MA, Sarfraz M. Natural cures for breast cancer treatment. Saudi Pharmaceutical Journal. 2016;24(3):233-240. Dove Medical Press encourages responsible, free and frank academic debate. The content of the Breast Cancer: Targets and Therapy 'letters to the editor' section does not necessarily
represent the views of Dove Medical Press, its officers, agents, employees, related entities or the Breast Cancer: Targets and Therapy editors. While all reasonable steps have been taken to
confirm the content of each letter, Dove Medical Press accepts no liability in respect of the content of any letter, nor is it responsible for the content and accuracy of any letter to the editor.

\section{Publish your work in this journal}

Breast Cancer - Targets and Therapy is an international, peerreviewed open access journal focusing on breast cancer research, identification of therapeutic targets and the optimal use of preventative and integrated treatment interventions to achieve improved outcomes, enhanced survival and quality of life for the cancer patient.
The manuscript management system is completely online and includes a very quick and fair peer-review system, which is all easy to use. Visit http://www.dovepress.com/testimonials.php to read real quotes from published authors. 